\title{
Clinical utility gene card for: von Willebrand disease
}

\author{
Anthony M Cumming ${ }^{\star, 1}$, Stephen Keeney ${ }^{1}$, P Vincent Jenkins ${ }^{2}$, Michael J Nash ${ }^{1}$ and James S O’Donnell ${ }^{2}$ \\ European Journal of Human Genetics (2011) 19; doi:10.1038/ejhg.2010.222; published online 5 January 2011
}

\section{DISEASE CHARACTERISTICS}

1.1 Name of the disease (synonyms)

von Willebrand disease (VWD).

\subsection{OMIM\# of the disease}

193400.

1.3 Name of the analysed genes or DNA/chromosome segments von Willebrand factor $(V W F)$.

\subsection{OMIM\# of the gene(s)}

193400.

\subsection{Mutational spectrum}

VWD, the most common inherited bleeding disorder in humans, is a heterogeneous disorder caused by a partial quantitative (type 1 VWD), qualitative (type 2 VWD) or severe quantitative (type 3 VWD) deficiency of von Willebrand factor protein (VWF). VWF has a central role in primary haemostasis, in which it functions at sites of vascular injury in an adhesive matrix between platelets and subendothelial components. VWF also functions as a carrier for coagulation factor VIII (FVIII) in the circulation, protecting FVIII from proteolytic degradation and localising it to the site of vascular injury. The VWF gene (VWF) is located at the short arm of chromosome 12 (12p13.2). It is a large gene comprising $\sim 178 \mathrm{~kb}$ of genomic DNA, including 52 exons varying in size from 40 to 1379 bases. ${ }^{1}$ The genetic regulation of plasma VWF levels is complex and involves genes other than VWF. A non-coding partial VWF pseudogene ( VWFP), spanning $25 \mathrm{~kb}$ of DNA and showing 97\% sequence homology with exons 23-34 of $V W F$, is located at chromosome 22q11.2. ${ }^{2}$ Careful design of PCR primers and protocols is required to avoid the inadvertent amplification of nucleic acid sequence from VWFP.

Type 1 VWD, a mild or moderate bleeding disorder, represents about $70 \%$ of cases of VWD. Diagnosis of type 1 VWD is often not straightforward, and the disorder is marked by incomplete penetrance and variable expressivity. In recent years, three large population-based studies in Europe, Canada and the United Kingdom ${ }^{3-5}$ have been carried out to investigate the molecular genetic basis of type 1 VWD. The main findings of these three studies, which were notably consistent, were:

- In type 1 VWD cases candidate mutations were present throughout the 'essential regions' (coding region, promoter or splice sites) of VWF.
- About $65 \%$ of candidate mutations were missense substitutions.

- There was no identified candidate mutation in the essential regions of $V W F$ in $>30 \%$ of cases.

- More than one candidate VWF mutation was identified in $15-20 \%$ of cases.

- Candidate VWF mutations were unlikely to be found in milder cases.

- Type 1 VWD may not be linked to VWF in 40 to $50 \%$ of cases.

- Currently unrecognised genetic loci, other than VWF, are implicated in the pathogenesis of type $1 \mathrm{VWD}$.

Type 2 VWD has four diagnostic sub-categories, defined by the results of VWF phenotypic assays - types $2 \mathrm{~A}, 2 \mathrm{~B}, 2 \mathrm{M}$ and $2 \mathrm{~N}$. Inheritance in types $2 \mathrm{~A}, 2 \mathrm{~B}$ and $2 \mathrm{M}$ VWD is autosomal dominant, whereas type $2 \mathrm{~N}$ VWD is a recessive disorder. Phenotypic penetrance in type $2 \mathrm{VWD}$ is high, with largely consistent expressivity of specific VWF mutations.

Type 2A VWD results from defective platelet-dependent function of VWF due to the absence of functionally essential high-molecular weight multimers of VWF. VWF mutations in type 2A VWD cause either intracellular retention (group 1 mutations) or lead to increased proteolysis (group 2 mutations) of high-molecular weight multimers. Approximately $85 \%$ of type $2 \mathrm{~A}$ VWD mutations are missense substitutions located in exon 28 of $V W F^{6}$

Type 2B VWD results from missense mutations in the platelet glycoprotein-Ib-binding region of VWF, located within the Al domain of the protein. These mutations give rise to a 'gain-in-function' of VWF by promoting the interaction between VWF and platelets. Circulating platelets become coated with mutant VWF, interfering with platelet adhesion at sites of injury and causing variable thrombocytopenia due to the sequestration of VWF-platelet aggregates in the microcirculation. Reported mutations in type $2 \mathrm{~B} \mathrm{VWD},{ }^{6}$ with a single exception, are missense substitutions in exon 28 of VWF.

Type $2 \mathrm{M}$ VWD is associated with reduced platelet-dependent function of VWF. Unlike type 2A VWD, high-molecular weight multimers of VWF are present. VWF mutations in type 2M VWD are located predominantly in the VWF A1 domain ${ }^{6}$ and cause defective interaction between VWF and platelet glycoprotein Ib. Type $2 \mathrm{M}$ VWD may also result from mutations in the $\mathrm{A} 3$ domain of VWF, which reduce binding of VWF to collagen, ${ }^{6}$ consequently reducing platelet adhesion.

The phenotype in individuals with type $2 \mathrm{~N}$ VWD is very similar to that seen in mild haemophilia A. Platelet-dependent function of VWF is normal but circulating levels of FVIII are low. This is the result of defective binding of FVIII by VWF due to mutations mostly located in 
the N-terminus FVIII-binding region of $V W F^{6}$ The recognition of type $2 \mathrm{~N}$ VWD and its differentiation from X-linked haemophilia A or haemophilia A carriership is required for valid genetic counselling, accurate carrier diagnosis and appropriate treatment of bleeding episodes.

Type 3 VWD is associated with moderate-to-severe bleeding symptoms, including epistaxis, menorrhagia, arthropathy and postoperative bleeding. Inheritance is autosomal recessive. Mutations in patients with type 3 VWD have been identified throughout the $178 \mathrm{~kb}$ length of the VWF locus, including the promoter region, coding and non-coding regions, and the $5^{\prime}$ and $3^{\prime}$ untranslated regions. ${ }^{6}$ Affected individuals are either homozygous (frequently the case in consanguineous kindreds) or compound heterozygous for VWF mutations. Approximately $80 \%$ of mutations in type 3 VWD give rise to a $V W F$ null allele, that is, nonsense mutations, deletions, splice-site mutations and small insertions. Missense changes account for only about $20 \%$ of the mutations associated with type $3 \mathrm{VWD}$. This is unlike type $1 \mathrm{VWD}$, in which approximately two-thirds of reported mutations are missense in nature. The genetic basis of type 3 and type 1 VWD is different in most cases. ${ }^{7}$

\subsection{Analytical methods}

Direct DNA sequence analysis of the essential regions of VWF is the method of choice for mutation detection in VWD. Targeted screening for VWF mutations in type 2 VWD may be carried out by PCR amplification and DNA sequencing of the relevant regions of VWF. In types $2 \mathrm{~A}, 2 \mathrm{~B}$ and $2 \mathrm{M}$ VWD, screening of exon 28 is recommended. A small proportion of mutations in type $2 \mathrm{~A}$ VWD are found outside exon 28 , therefore, extended screening may be required if the exon 28 sequence is normal. In type $2 \mathrm{~N}$ VWD, the minimum extent of sequencing should encompass exons 18-20, encoding the VWFFVIII-binding domain. Occasional mutations have been reported in type 2N VWD outwith this region (exons 17 and 24-27), hence, targeted analysis of exons 18-20 cannot completely exclude this disorder. Mutation detection strategies are fully discussed in a current practise guideline for the molecular analysis of VWD. ${ }^{8}$

\subsection{Analytical validation}

Recommended practise, including analytical design, mutation validation procedures and analytical pitfalls, is discussed in a current practise guideline for the molecular analysis of VWD. ${ }^{8}$ External quality assurance (EQA) should be carried out where this is available, and an EQA scheme has been established for genetic investigation of VWD (and haemophilia).

Details of this scheme are available from United Kingdom NEQAS for blood coagulation (URL: http://www.ukneqasbc.org/content/ PageServer.asp? $S=932234149 \& C=1252 \& I D=32)$. Internal quality control is achieved by the use of anonymous reference mutants.

\subsection{Estimated frequency of the disease}

(incidence at birth (birth prevalence) or population prevalence)

The reported prevalence of VWD depends on the phenotypic diagnostic criteria used. Estimates based on the number of patients with bleeding symptoms seen in haemostasis outpatient clinics range from 23 per million $(0.0023 \%)$ to 110 per million $(0.011 \%)$ of the population. ${ }^{9}$ Population-based estimates of the prevalence of VWD have been much higher, with a reported range of between 0.6 and $1.2 \%{ }^{10}$ The diagnosis of VWD is influenced by exposure to haemostatic challenges, and because of this more women than men are diagnosed. VWF levels are related to ABO blood group-proportionately more blood group $\mathrm{O}$ individuals are diagnosed to have type 1
VWD. Type 3 VWD, the most severe of the VWD variants, is a rare disorder with a prevalence of $0.5-1$ individual per million in the general population, ${ }^{11}$ although this may be as high as 6 per million in populations where consanguinity is common. ${ }^{9}$

\subsection{If applicable, prevalence in the ethnic group of investigated person}

ABO blood group is a known modifier of VWF levels, with the lowest levels being present in group $\mathrm{O}$ individuals. $\mathrm{ABO}$ blood group frequencies vary across ethnic groups, hence, it is possible that more cases of type 1 VWD will be diagnosed in populations with a high prevalence of group $\mathrm{O}$ individuals. The published data indicate, however, that the prevalence of VWD is similar in different ethnic groups. ${ }^{12}$ As mentioned in 1.8 above, type 3 VWD occurs with an increased frequency in populations where consanguinity is common.

\subsection{Diagnostic setting}

\begin{tabular}{lcc}
\hline & Yes & No \\
A. (Differential) diagnostics & $\square$ & $\square$ \\
B. Predictive Testing & $\square$ & $\square$ \\
C. Risk assessment in relatives & $\square$ & $\square$ \\
D. Prenatal & $\square$ & $\square$ \\
\hline
\end{tabular}

Comment:

In type $1 \mathrm{VWD}$ there is generally little justification for genetic diagnosis. There is, however, some debate in the literature about this. ${ }^{13,14}$ In mild type 1 VWD cases with VWF levels $>40 \mathrm{IU} / \mathrm{dL}$, the diagnosis or exclusion of VWD is often difficult. VWF levels often do not segregate with bleeding, and modifiers including $\mathrm{ABO}$ blood group have a substantial effect on VWF levels. A VWF mutation is unlikely to be found in these cases and genetic studies have little utility to contribute to diagnosis. In type 1 VWD cases with VWF levels $<30 \mathrm{IU} / \mathrm{dL}$ phenotypic diagnosis is usually straightforward and there is little need to screen patients or family members for a causative mutation. Treatment of these patients relates to the presenting level of VWF and clinical phenotype rather than to the genetic mutation. There may be a role for genetic testing in more severe forms of type 1 $\mathrm{VWD},{ }^{8}$ for example in individuals with VWF levels $<15 \mathrm{IU} / \mathrm{dL}$ wherein $>90 \%$ of cases have highly penetrant VWF mutations. Screening for the VWD Vicenza variant (p.Arg1205His), which is associated with a reduced VWF survival time in the circulation, may be useful in these patients as a confirmed diagnosis of VWD Vicenza may influence patient management. There is no indication for prenatal diagnosis in type 1 VWD.

In most cases of type 2 VWD diagnosis and classification is made using the results of phenotypic tests. There is, however, a clear role for genetic testing to screen for type $2 \mathrm{~N}$ VWD in patients with FVIII deficiency which may not be X-linked, or in families where a factor VIII gene (F8) mutation cannot be identified, and also for the discrimination of type $2 \mathrm{~B} \mathrm{VWD}$ and platelet-type pseudo-VWD (defect of platelet glycoprotein Ib with a laboratory phenotype very similar to type 2B VWD) wherein phenotypic discrimination may be less straightforward. Genetic testing is also useful in the discrimination of various type 2 VWD types from each other, or from type 1 VWD.

In diagnostic testing for type $3 \mathrm{VWD}$, wherein VWF levels are markedly low or absent, phenotypic analysis generally gives clear-cut results in affected individuals. Genetic diagnosis and associated family studies are, however, important tools to inform genetic counselling of affected families. Genetic diagnosis allows the identification of 
asymptomatic carriers of type $3 \mathrm{VWD}$ as this diagnosis cannot be made by phenotypic testing or, frequently, by pedigree analysis. Knowledge of the familial VWF mutation(s) provides valuable information to help family members with family planning decisions, including making informed decisions about prenatal diagnosis or possibly preimplantation genetic diagnosis. Furthermore, awareness of the type 3 VWD carrier status of the parents, together with knowledge of the likelihood of the birth of an affected child, provides important information to clinicians involved with the management of childbirth and the postnatal care of the neonate. Knowledge of the mutation type provides information about the risk of the development of anti-VWF antibodies and the consequential risk for anaphylactic reactions associated with VWF replacement therapy. ${ }^{15}$

\section{TEST CHARACTERISTICSES}

\begin{tabular}{|c|c|c|c|c|}
\hline & \multicolumn{2}{|c|}{ Genotype or disease } & \multirow{2}{*}{$\begin{array}{l}\text { A: True positives } \\
\text { B: False positives }\end{array}$} & \multirow{2}{*}{$\begin{array}{l}\text { C: False negative } \\
\text { D: True negative }\end{array}$} \\
\hline & Present & Absent & & \\
\hline \multicolumn{5}{|l|}{ Test } \\
\hline \multirow[t]{2}{*}{ Positive } & A & B & Sensitivity: & $A /(A+C)$ \\
\hline & & & Specificity: & $D /(D+B)$ \\
\hline \multirow[t]{2}{*}{ Negative } & c & D & Positive predictive value: & $A /(A+B)$ \\
\hline & & & Negative predictive value: & $D /(C+D)$ \\
\hline
\end{tabular}

\subsection{Analytical sensitivity}

(proportion of positive tests if the genotype is present)

Type 1 VWD - genetic testing not generally applicable

(see 1.10 above).

Type 2 VWD - up to $100 \%{ }^{16}$

Type 3 VWD $-81 \%$ to $100 \%{ }^{17-19}$

\subsection{Analytical specificity}

(proportion of negative tests if the genotype is not present)

Type 1 VWD - genetic testing not generally applicable

(see 1.10 above).

Types 2 and 3 VWD - genetic testing would be expected to be negative in the absence of the disease. Genetic testing is not generally indicated until the diagnosis has already been made by phenotypic means.

\subsection{Clinical Sensitivity}

(proportion of positive tests if the disease is present)

The clinical sensitivity can be dependent on variable factors such as age or family history. In such cases, a general statement should be given, even if a quantification can only be made case by case. Type 1 VWD - genetic testing not generally applicable

(see 1.10 above).

Type 2 VWD - up to $100 \% .^{16}$

Type 3 VWD - $081 \%$ to $100 \% .{ }^{17-19}$

\subsection{Clinical specificity}

(proportion of negative tests if the disease is not present)

The clinical specificity can be dependent on variable factors, such as age or family history. In such cases, a general statement should be given, even if a quantification can only be made case by case.

Type 1 VWD - genetic testing not generally applicable (see 1.10 above).

Types 2 and 3 VWD - genetic testing would be expected to be negative in the absence of the disease. Genetic testing is not generally indicated until the diagnosis has already been made by phenotypic means.

\subsection{Positive clinical predictive value}

(life-time risk to develop the disease if the test is positive)

Not applicable. VWD is present from birth. The primary diagnosis is made by clinical presentation and laboratory phenotypic testing.

\subsection{Negative clinical predictive value}

(probability not to develop the disease if the test is negative)

Assume an increased risk based on family history for a non-affected person. Allelic and locus heterogeneity may need to be considered. Index case in that family had been tested:

Not applicable - see 2.5 above.

Index case in that family had not been tested:

Not applicable - see 2.5 above.

\section{CLINICAL UTILITY}

3.1 (Differential) diagnosis: The tested person is clinically affected (To be answered if in 1.10 ' $\mathrm{A}$ ' was marked)

\subsubsection{Can a diagnosis be made other than through a genetic test?}

$\begin{array}{ll}\text { No } & \square \text { (continue with 3.1.4) } \\ \text { Yes } & \text { Clinically } \\ \text { Imaging } & \square \\ \text { Endoscopy } & \square \\ \text { Biochemistry } & \square \\ \text { Electrophysiology } & \square \\ \text { Other (please } & \text { Q The diagnosis and classification of von Willebrand disease } \\ \text { describe) } & \text { is usually made by means of phenotypic laboratory assays of } \\ & \text { von Willebrand factor function, von Willebrand factor levels in } \\ & \text { plasma and von Willebrand factor multimer analysis. }\end{array}$

3.1.2 Describe the burden of alternative diagnostic methods to the patient

Attendance at outpatient clinics and collection of blood samples for analysis.

3.1.3 How is the cost effectiveness of alternative diagnostic methods to be judged?

Genetic diagnostic testing is likely to be significantly more expensive than phenotypic analysis, and should only be used in appropriately selected cases, in whom the results may directly influence diagnosis and/or management (see Comment, section 1.10).

3.1.4 Will disease management be influenced by the result of a genetic test?

\begin{tabular}{|c|c|}
\hline No & $\square$ \\
\hline Yes & $\otimes$ \\
\hline $\begin{array}{l}\text { Therapy } \\
\text { (please describe) }\end{array}$ & $\begin{array}{l}\text { Therapy may be influenced in type } 2 \text { von Willebrand disease } \\
\text { depending on the differential diagnosis, which may be made } \\
\text { as a result of genetic diagnostic testing, for example, to } \\
\text { diagnose type } 2 \mathrm{~N} \text { von Willebrand disease, or to distinguish } \\
\text { type } 2 \mathrm{~B} \text { von Willebrand disease and platelet-type pseudo von } \\
\text { Willebrand disease (see } 1.10 \text { above). }\end{array}$ \\
\hline $\begin{array}{l}\text { Prognosis } \\
\text { (please describe) }\end{array}$ & Not influenced \\
\hline $\begin{array}{l}\text { Management } \\
\text { (please describe) }\end{array}$ & As for therapy \\
\hline
\end{tabular}


3.2 Predictive setting: The tested person is clinically unaffected but carries an increased risk based on family history

(To be answered if in 1.10 'B' was marked)

\subsubsection{Will the result of a genetic test influence lifestyle and prevention?}

If the test result is positive or negative (please describe).

Diagnosis of VWD is by phenotypic means in the large majority of cases. However, in families wherein type 3 VWD is present knowledge of carriership or non-carriership for the mutation(s) may influence family planning.

3.2.2 Which options in view of lifestyle and prevention does a person at-risk have if no genetic test has been done (please describe)?

The absence of genetic testing is not a factor which would be considered to influence lifestyle in individuals with VWD.

3.3 Genetic risk assessment in family members of a diseased person (To be answered if in 1.10 ' $\mathrm{C}$ ' was marked).

3.3.1 Does the result of a genetic test resolve the genetic situation in that family?

In VWD subtypes with a clear genetic link to the phenotype (see section 2) the genetic situation will be resolved. This is particularly relevant to some families with type 3 VWD.

3.3.2 Can a genetic test in the index patient save genetic or other tests in family members?

In dominant type $2 \mathrm{VWD}$ (type 2A, 2B, 2M) knowledge of the underlying VWF mutation in an index case can save genetic testing in other family members (see also 1.10 above).

3.3.3 Does a positive genetic test result in the index patient enable a predictive test in a family member?

This is possible; however primary diagnosis in VWD is by phenotypic means.

\subsection{Prenatal diagnosis}

(To be answered if in 1.10 ' $\mathrm{D}$ ' was marked).

3.4.1 Does a positive genetic test result in the index patient enable a prenatal diagnosis?

Yes, but PND is applicable only in type 3 VWD.

\section{IF APPLICABLE, FURTHER CONSEQUENCES OF TESTING}

Please assume that the result of a genetic test has no immediate medical consequences. Is there any evidence that a genetic test is nevertheless useful for the patient or his/her relatives? (Please describe).

The results of genetic testing can be useful in type 3 VWD to allow asymptomatic carriers of this disorder to be identified within an affected family as carrier diagnosis cannot be made by phenotypic testing or, frequently, by pedigree analysis. The results of genetic testing can provide valuable information to help family members with family planning decisions, including making informed decisions about the option for prenatal diagnosis.

\section{CONFLICT OF INTEREST}

The authors declare no conflict of interest.

\section{ACKNOWLEDGEMENTS}

This work was supported by EuroGentest, an EU-FP6 supported NoE, contract number 512148 (EuroGentest Unit 3: 'Clinical genetics, community genetics and public health', Workpackage 3.2).

1 Mancuso DJ, Tuley EA, Westfield LA et al: Structure of the gene for human von Willebrand factor. J Biol Chem 1989; 264: 19514-19527.

2 Mancuso DJ, Tuley EA, Westfield LA et al: Human von Willebrand factor gene and pseudogene: structural analysis and differentiation by polymerase chain reaction. Biochemistry 1991; 30: 253-269.

3 Goodeve A, Eikenboom J, Castaman G et al: Phenotype and genotype of a cohort of families historically diagnosed with type 1 von Willebrand disease in the European study, molecular and Clinical markers for the diagnosis and management of type 1 von Willebrand disease (MCMDM-1VWD). Blood 2007; 109: 112-121.

4 James PD, Notley C, Hegadorn $C$ et al: The mutational spectrum of type 1 von Willebrand disease: results from a Canadian cohort study. Blood 2007; 109: 145-154.

5 Cumming A, Grundy P, Keeney $S$ et al: An investigation of the von Willebrand factor genotype in UK patients diagnosed to have type 1 von Willebrand disease. Thromb Haemost 2006; 96: 630-641.

6 ISTH SSC VWF Database, http://www.vwf.group.shef.ac.uk/.

7 Cumming AM, Sutherland MS, Keeney S: The molecular basis of type 3 von Willebrand disease. J Coag Dis 2010; 2: 29-35.

8 Keeney S, Bowen D, Cumming A et al: The molecular analysis of von Willebrand disease: a guideline from the UK Haemophilia Centre Doctors' Organisation Haemophilia Genetics Laboratory Network. Haemophilia 2008; 14: 1099-1111.

9 Sadler JE, Mannucci PM, Berntorp E et al: Impact, diagnosis and treatment of von Willebrand disease. Thromb Haemost 2000; 84: 160-174.

10 Rodeghiero F, Castaman G, Dini E: Epidemiological investigation of the prevalence of von Willebrand's disease. Blood 1987; 69: 454-459.

11 Mannucci PM, Bloom AL, Nilsson IM et al: Atherosclerosis and von Willebrand factor I. Prevalence of severe von Willebrand's disease in western Europe and Israel. Br J Haematol 1984; 57: 163-169.

12 Rodeghiero F, Castaman G: Congenital von Willebrand disease type 1: definition, phenotypes, clinical and laboratory assessment. Best Pract Res Clin Haematol 2001; 14: 321-335.

13 Favaloro EJ: Genetic testing for von Willebrand disease: the case against. J Thromb Haemost 2010; 8: 6-12.

14 Peake IR, Goodeve AC: Genetic testing for von Willebrand disease: the case for. J Thromb Haemost 2010; 8: 13-16.

15 Mannucci PM: Genetic testing in von Willebrand disease: a rebuttal. $J$ Thromb Haemost 2010; 8: 860.

16 Goudemand J, Fressinaud E, Boisseau P et al: Distribution of von Willebrand disease (VWD) types in 94 families from the French National Reference Center for VWD (CRMW): type 1 is not the most frequent within "true" VWD. J Thromb Haemost 2009; 7(Suppl 2): Abstract PP-TH-623.

17 Sutherland MS, Keeney S, Bolton-Maggs PHB et al: The mutation spectrum associated with type 3 von Willebrand disease in a cohort of patients from the North West of England. Haemophilia 2009; 15: 1048-1057.

18 Gupta PK, Saxena R, Adamtziki E et al: Genetic defects in von Willebrand disease type 3 in Indian and Greek patients. Blood Cells Mol Dis 2008; 41: 219-222.

19 Baronciani L, Cozzi G, Canciani MT et al: Molecular defects in type 3 von Willebrand disease: updated results from 40 multiethnic patients. Blood Cells Mol Dis 2003; 30: 264-270. 